\section{Chronic Regulatory Focus: Resist impulse consumption or let it happen?}

\author{
Marconi Freitas da Costa ${ }^{1}$ \\ Salomáo Alencar de Farias ${ }^{1}$ \\ ${ }^{1}$ Federal University of Pernambuco, Management Department, Recife, Brazil \\ Claudio Felisoni de Angelo ${ }^{2}$ \\ ${ }^{2}$ University of São Paulo, Management Department, São Paulo, Brazil
}

Received on $11 / 03 / 2017$

Approved on 06/08/2018

Responsible editor:

Prof. Dr. João Mauricio Gama

Boaventura

\section{Evaluation process:}

Double Blind Review

\begin{abstract}
Purpose - The central objective of this research was to analyze the moderating role of chronic regulatory focus in impulse consumption when individuals are exhausted of self-control energies (ego depletion). In addition, we sought to examine the relationship between regulatory adjustment and the affective and cognitive processes of impulse decision making.
\end{abstract}

Design/methodology/approach - The study was performed through an experiment. Data analysis was done using the Johnson-Neyman floodlight technique, which is recommended when the independent variable is continuous, so as not to transform it into a dichotomous variable, thus avoiding the loss of information.

Findings - The results provide evidence that individuals with a profile of being vigilant about impulse decisions (focus on prevention), that is, with greater self-control in their decisions, end up spending more self-control energy than individuals who do not have this concern (focus on promotion), resulting in higher impulse consumption.

Originality/value - The main contribution is a counterintuitive result that individuals who should be better prepared to withstand impulse consumption, with greater self-control, end up consuming more on impulse because they expend more energy in an attempt to control themselves.

Keywords - Chronic regulatory focus; Ego depletion; Impulse consumption.

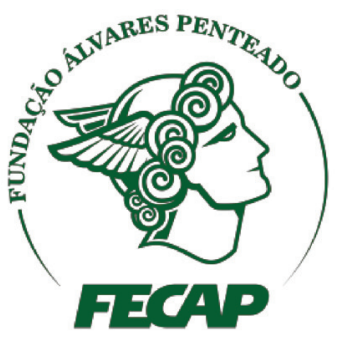

Review of Business Management

DOI: $10.7819 /$ rbgn.v0i0.3954 


\section{Introduction}

Consumer behavior studies address the different complexities of the individual with regard to purchase decisions and impulse consumption. These studies have been systematized in recent decades, with classic themes such as attitudes, perception, extended self, and references groups, among others (Costa \& Farias, 2016). In this article, the interest is on the regulatory focus of individuals and the ego depletion (self-control energy expenditure) in impulse consumption decision processes.

The everyday environment is full of temptations, as can be seen in supermarket aisles, online shopping websites, and coffee shops. These places are full of tempting products (Hur, Koo, \& Hofmann, 2015), often resulting in a struggle between impulses and self-control in the minds of consumers. Consumers thus struggle to restrain the desires which drive the consumption of tempting products because it interferes with their long-term goals, often losing in this struggle and failing at self-control (Baumeister, 2002; Yim, 2017).

The failure of self-control has a close relationship with impulse decisions (Vohs \& Faber, 2007). Research on impulse decisions has intensified in the last 20 years (Amos, Holmes, \& Keneson, 2015; Costa, Paula, Angelo, \& Fouto, 2017; Dholakia, 2000; Rook \& Fisher, 1995). Impulse consumption happens repeatedly and has negative consequences for consumers (Badgaiyan \& Verma, 2015), such as, e.g., the difficulty that individuals face when controlling their weight, when they cannot resist the temptations of impulse consumption (Achtziger, Hubert, Kenning, Raab, \& Reisch, 2015).

Due to the difficulties and challenges encountered with impulse decisions, the principles, or the basis that supports the behavior, inherent to the individual's self-control, have aroused the interest of researchers in the field of psychology for some time, especially in understanding the nature of the motivations that drive people in the pursuit of their goals (Higgins, 1997; Kuhl, 1981). Regulatory focus theory has helped in this understanding and has been gaining more space in consumer behavior research (Avnet $\&$ Higgins, 2006; Haws, Dholakia, \& Bearden, 2010; Rajat, 2017).

Regulatory focus is a specific strategy and motivational guidance that the individual adopts during the pursuit of his or her ideals or duties (Higgins, 1997). Two types of regulatory focus can be distinguished, according to Pham and Chang (2010): a focus on promotion, which emphasizes strategies aimed at achieving desired outcomes, and a focus on prevention, which emphasizes strategies aimed at avoiding unwanted outcomes. In addition, regulatory focus is a state that can be investigated both as a chronic tendency, developed throughout the individual's life, and as a situationinduced (manipulated) focus (Haws, Dholakia, \& Bearden, 2010).

Another theory which, by its characteristics, appears to be related to impulse decisions is the theory of ego depletion (Itzchakov, Uziel, \& Wood, 2018). This theory is based on the limited resources individuals have to maintain self-control (Sjastad \& Baumeister, 2018). On ego depletion, Baumeister (2002) states that the individual's ability to maintain self-control is limited, because by expending energy in an activity that requires self-control, he or she will lack energy to maintain self-control in subsequent activities.

After reviewing the literature on ego depletion, regulatory focus, and impulse consumption, a theoretical gap has been perceived: the effects of ego depletion, and the lack of energy to maintain self-control, could perhaps be attenuated by some chronic characteristic of individuals in impulse consumption situations. Decisions by impulse, whether purchasing or consumption ones, usually happen in situations where people have few self-control resources. Thus, it is believed that there are characteristics of individuals developed throughout their lives that may help in the control of decisions and others that can impair their performance. 
These characteristics may be related to chronic regulatory focus theory, where individuals are already accustomed to seizing opportunities (focus on promotion), which may lead them to consume further on impulse, or their behavior is rooted in trying to avoid a negative situation (focus on prevention), which may help with resisting the impulsive temptations of consumption.

In view of the above, the following research question was identified: How can the chronic regulatory focus of the individual act as a moderator of the relationships between ego depletion and impulse consumption decisions? The importance of this study lies in its analysis of the moderating role of the two different chronic regulatory focuses, promotion and prevention, in mitigating the effects that individuals suffer from the depletion of self-control energies in impulse consumption decisions. It is believed that the different ways that individuals seek to achieve their ideals and duties, which is a premise of regulatory focus, would increase or decrease (depending on the focus) the effects of ego depletion on impulse consumption decisions.

Moreover, impulse decisions present an important characteristic based on two processes (or components): the affective process, which is based on the emotions and mood states of individuals, and the cognitive process, which, in turn, has as its foundation the mental structures and processes involved in thinking, understanding, and interpreting (Youn, 2000). Thus, the research also sought to analyze the adjustment of chronic regulatory focus with the affective and cognitive processes of impulse decisions, considering that the focus on promotion is more linked to the affective process and the focus on prevention relates more to the cognitive process.

\section{Literature Review}

\section{I Chronic Regulatory Focus and the Impulse Decision Components}

Psychologists have long been interested in the principles of self-regulation, especially in the nature of the movements that have been stimulated in relation to the representation of individuals' end states (Akhtar \& Lee, 2014; Carver \& Scheier, 1990; Higgins, Roney, Crowe, \& Hymes, 1994; Kuhl, 1984). The studies have progressed and, according to Higgins et al. (1994), two basic distinctions regarding self-control have been established in the literature. One relates to the valence of the end state that functions as the reference value for the movement (positive versus negative) and one involves the direction of the movement that has been stimulated (approach versus avoidance). It is worth mentioning that the concept of valence, as used in psychology, is the intrinsic attractiveness (positive valence) or averseness (negative valence) of an event, object, or situation (Galbraith \& Cummings, 1967).

On valence, according to Malaviya and Brendl (2014), the self-regulatory system may have a desired end state (i.e., positive reference value) or an unwanted end state (i.e., negative reference value) functioning as a standard. Also, in relation to the direction of the movement that has been stimulated, the literature distinguishes approach as being a positive state of the person and avoidance as being a negative state (Higgins et al., 1994; Lai, Hsu, \& Li, 2018).

Certain modes of interaction between parents and children increase the likelihood that children will achieve a strong desired end state (Manian, Papadakis, Strauman, \& Essex, 2006). This desired end state, according to Pham and Chang (2010), represents the hopes, desires, and aspirations of individuals (strong ideals) or obligations and responsibilities (strong duties). These different ways of representing the desired end state are the basis of regulatory focus theory, which is subdivided into regulatory focus on promotion and regulatory focus on prevention (Bullard \& Manchanda, 2017). Self-regulation based on ideals involves regulatory focus on promotion; whereas self-regulation based on duties involves regulatory focus on prevention (Chan \& Ho, 2017).

Regulatory focus can be manipulated or it can be chronic (Haws, Dholakia, \& Bearden, 
2010). The latter is developed throughout the years in the routines of individuals and is part of the socialization process (Coley \& Burgess, 2003). The different socializations encompassed in parents-children relationships allow us to understand how chronic regulatory focus distinguishes between different types of selfregulation in relation to the desired end state (Higgins, 1997; Haws, Dholakia, \& Bearden, 2010). Children learn from these interactions to self-regulate in relation to the ideals of the promotion focus or the duties of the prevention focus (Manian et al., 2006). In general, two forms of desired end states are identified: (a) aspirations and accomplishments (regulatory focus on promotion) and (b) responsibilities and safety (regulatory focus on prevention) (Graham, Ziegert, \& Capitano, 2015).

Within the general approach to the desired end state, chronic regulatory focus may induce strategic inclinations of approach or avoidance (Akhtar \& Lee, 2014; Hong \& Lee, 2008). According to Higgins (1997), as a focus on promotion involves sensitivity to positive outcomes (their presence and absence), a bias towards approach that matches the desired end state is the natural strategy for self-regulation with a focus on promotion. In turn, because a focus on prevention involves sensitivity to negative outcomes (their absence and presence), a bias towards avoidance that does not match the desired end state is the natural strategy for self-regulation focused on prevention (Dholakia et al. al., 2006).

From the theory of chronic regulatory focus, another concept has gained strength among researchers (Avnet \& Higgins, 2003; Katsikeas, Auh, Spyropoulou, \& Menguc, 2018; Pham \& Chang, 2010): regulatory adjustment. The advances in the theory of regulatory focus try to explain the correctness of types of objectives (Cesario, Higgins, \& Scholer, 2008) and the strategies used to achieve them in the form of regulatory adjustment (Lai, Hsu, \& Li, 2018). According to Higgins (2000), the adjustment of regulatory focus is a theory of pursuing goals that places particular emphasis between the actor's motivational orientation and his or her pursuit of goals (e.g., the strategic means used by the actor).

The experience of regulatory adjustment strengthens a person's motivational involvement in the choice process, thereby enhancing the pulling force exerted by choice options (Pham \& Chang, 2010). Moreover, regulatory adjustment may stimulate a hedonic experience of "feeling right", which tends to increase the perceived value of the objects for which this feeling is attributed (Dam \& Jonge, 2015). For Higgins and Scholer (2009), the strength of involvement and the "feeling right" experience that results from regulatory adjustment situations can increase the perceived value of an object.

The different forms used by individuals in the search for a desired end state may lead them to have more interest in consuming products with characteristics that converge with their regulatory focus. According to Lucas and Koff (2017), the impulse to consume a given product has a strong relation to the appeal it exerts over the individual, which can be a rational or emotional appeal. Stimuli, whether rational or emotional, can drive individuals to make decisions by impulse, i.e., without much deliberation (Broonchoo \& Thoumrungroje, 2017).

An important aspect of impulse decisions addressed by Youn (2000) is that they are made up of two processes: the affective process and the cognitive process. The affective process relates to emotions and states of mood. The cognitive process refers to the mental structures and processes involved in thinking, understanding, and interpreting (Costa, Patriota, \& Angelo, 2017). Although they are conceptually distinguishable, affective (emotional) processes, which create impulsivity, and cognitive (rational) processes, which allow self-control, are not independent from each other (Coley, 2002; Verhagen \& Dolen, 2011).

Recognition of the need to balance the different, but complementary, roles that reasons and emotions play in active and reactive 
consumption experiences is imperative for understanding the dynamics of impulse purchase phenomena and the internal conflict between the two motives (Coley, 2002; Youn, 2000). The degree to which impulsivity happens strongly depends on these two processes: affective impulsiveness and cognitive self-control. As the intensity of one process increases, and takes over, the other diminishes, and subsides (Youn, 2000).

As observed, previous research (Avnet $\&$ Higgins, 2006; Hong \& Lee, 2008) has shown that individuals with one of two regulatory focuses present consistent adjustments in their decision making. People with a focus on promotion experience regulatory adjustment when making decisions based upon emotions or feelings, and people with a focus on prevention experience regulatory adjustment when making decisions based on reasons.

Thus, these decisions, which lead to regulatory adjustment, suggest that individuals with a regulatory focus on promotion would be more aligned to the affective components of impulse decisions, whereas a regulatory focus on prevention would be more convergent with the cognitive components of impulse decisions. Given the apparent conceptual relationship between the regulatory focuses and the affective and cognitive psychological processes involved in impulse decisions, a proposal emerges related to the possible adjustment of a focus on promotion using the affective components of impulsive decisions, as well as another proposition related to adapting a focus on prevention my means of cognitive components. Thus, two hypotheses were made to test the aforementioned propositions:

H1a: Individuals with a chronic regulatory focus on promotion will make a more positive assessment of the affective processes of impulse decisions.

H1b: Individuals with a chronic regulatory focus on prevention will make a more positive assessment of the cognitive components of impulse decisions.

\section{I Chronic Regulatory Focus, Ego Depletion, and Impulse Consumption}

According to the theory of chronic regulatory focus (Haws, Dholakia, \& Bearden, 2010; Higgins, 1997), the system of self-regulation based on a focus on promotion originates from the control of the needs for growth and from physical and emotional care and is especially active in the pursuit of "ideals" (i.e., desires, dreams, and aspirations). On the other hand, the system of selfregulation based on a focus on prevention originates from the control of the needs for protection and security and is more active in the pursuit of "duties" (i.e., responsibilities and obligations). According to Pham and Chang (2010), a major aspect of the focus on promotion, which is based on anxiety, is the drive to seize opportunities. In contrast, the focus on prevention, based on surveillance, is characterized by a strong concern for avoiding errors.

As self-regulation is people's attempt to control or change their own responses, since many responses have motivational strength, selfregulation willpower requires the expenditure of strength (a resource) in order to dominate them (Sjastad \& Baumeister, 2018). Thus, in the standard example about diet or about resisting many diverse temptations, one has to exert great effort to avoid a strong forbidden impulse (Vohs $\&$ Faber, 2007). This effort is a limited resource, leading to ego depletion.

Ego depletion refers to a diminished state of self-regulation powers resulting from a previous effort (Baumeister, Bratslasky, Muraven, \& Tice, 1998). The strength exerted to maintain self-control leads to ego depletion, because the resource needed for maintaining control is considered as limited, and weakens through attempts at self-regulation in subsequent tasks (Itzchakov, Uziel, \& Wood, 2018).

Baumeister et al. (1998) and Petrocelli, Williams, and Clarkson (2015) support the idea of a strength model, which implies that self-regulation willpower is a limited resource. At any given moment there is a fixed amount of 
regulatory willpower available for self-control: the activity of regulating a response may result in weaker control of another concurrent response (Muraven, Tice, \& Baumeister, 1998). It can be concluded that the self-control effort consumes a limited resource, which reduces the amount that will be available for other tasks, resulting in worse performance in these other regulation activities (Salmon et al., 2015). This resource can be considered self-regulation willpower.

Arguments about lack of energy to maintain self-control may have a direct relationship with impulse consumption decisions. An impulse decision involving either consumption or a purchase, happens, according to Rook (1987), when a consumer experiences a sudden, often strong and persistent impulse to purchase or consume something immediately. In accordance with Rook's definition (1987), Segunpta and Zhou (2007) define impulsive behavior as feeling a sudden and unplanned willingness to behave in a hedonically pleasant manner, which is immediately gratifying, and then acting on impulse, without careful deliberation on the subsequent negative consequences.

From these conceptualizations, it is believed that individuals in both regulatory focuses can moderate the effects of ego depletion in situations of impulse consumption. Considering only the direct ratio of ego depletion over impulse consumption, it can be inferred that individuals with the highest energy expenditure to maintain self-control in an ego-depleting activity will engage in additional impulse consumption of a tempting product. However, based on the different characteristics of regulatory focuses, it is believed that this ratio of individuals with low self-control energy to impulse consumption may be different.

For this research, the understanding is that individuals with a focus on prevention will have a greater expenditure of self-control energy, considering that this focus is always in a state of vigilance, which, in itself, already causes energy expenditure (Lee \& Aaker, 2004; MouakharKlouz, D’Astous, \& Darpy, 2016). Moreover, the addition of an ego-depleting activity will lead to a double expenditure for individuals with this focus. In contrast, individuals with a focus on promotion, due to not having this prerogative to maintain vigilance, can achieve lower levels of impulse consumption when self-control energies are low, compared to the focus on prevention.

The thought that a chronic focus on promotion will be able to mitigate the effects of ego depletion is due to the fact that this focus can further recover self-control energies, because the drive to seize opportunities does not cause major energy expenditures. Moreover, a chronic focus on prevention, because of the constant concern about maintaining vigilance in decisions, will intensify the expenditure of energy and, consequently, increase the amount of consumption by impulse of a product that arouses temptation. These arguments will be evaluated by the following hypothesis:

H2: The effects of ego depletion on impulse consumption will be attenuated by a chronic focus on promotion (consuming less on impulse) and further intensified by a chronic focus on prevention (consuming more by impulse).

The following is a theoretical model that aims to illustrate the main relationships between the constructs investigated by this study. According to the model, there is supposedly a direct relationship between the ego depletion of individuals and impulse consumption decisions, and this relationship is moderated by the regulatory focus of the individual. 


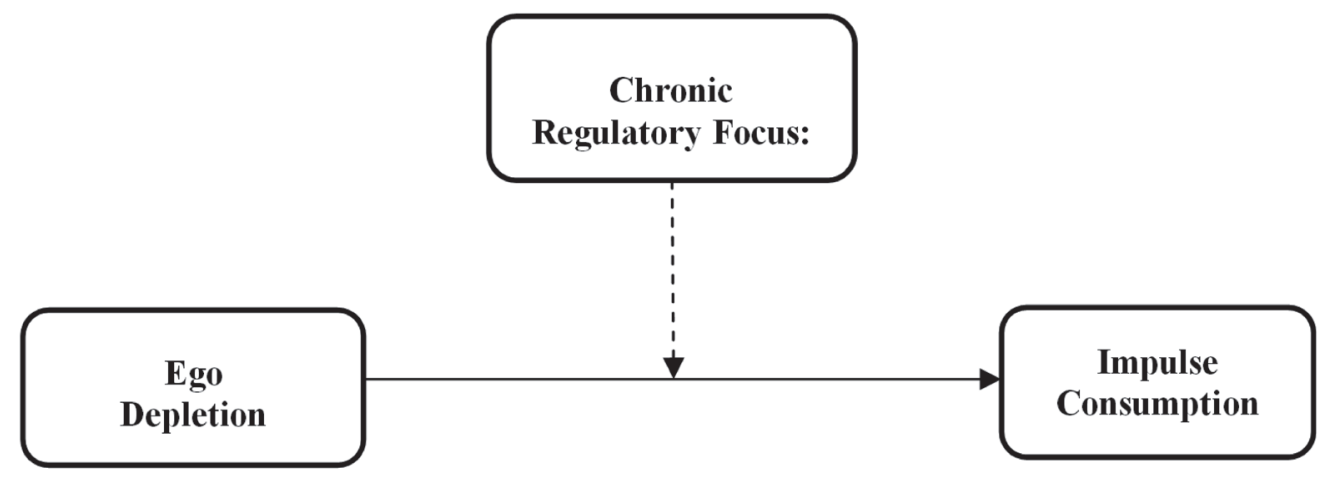

Figure 1. Theoretical model

In the theoretical model, a dashed line was used to represent the relations between the constructs. This line has the purpose of highlighting the relationship that has not yet been investigated by other research, allowing the visualization of the main contribution of this study, which was to analyze the moderating role of chronic regulatory focus in the relationship between ego depletion and impulse consumption decisions. In this topic of the paper, the hypotheses of the research were presented. In the next topic, the research method will be presented.

\section{Research Method}

This topic has the purpose of presenting the methodological procedures used to achieve the research objectives. This study was carried out through experimental research. The experiment that was developed in the study used an independent groups (between subjects) design and was done in controlled situations, with laboratory characteristics (Tabachnick \& Fidell, 2006).

Detailed information about the procedures that were performed in the experiment will be presented later. However, this research method topic presents the classification of variables and the sampling procedure, as well as the statistical techniques used.

The variables studied in this research can be classified as follows: regulatory focus (independent - H1a and H1b, moderator - H2), ego depletion (independent - H2), impulse consumption (dependent - H2), and the processes of impulse consumption (dependent - H1a and $\mathrm{H} 1 \mathrm{~b})$.

In order to define the sample size, the $\mathrm{G}^{*}$ Power software was used. Thus, considering the options for calculating the sample available in the program, the following was selected: effect size $f=$ $0.25 ; \mathrm{a}=0.05$; power $=0.80 ; d f=1$; number of groups $=4(2 \times 2$ design $)$ The sample determined by $\mathrm{G}^{*}$ Power had 128 participants. A minimum of 40 participants were established in each treatment group, considering that some questionnaires were excluded, and the design for this experiment was $2 \times$ continuous, thus totaling a sample of 160 .

The statistical techniques employed in this study were (Montgomery, 2012): the (nonparametric) Mann-Whitney U test, the Student's $t$ test, the Multiple Linear Regression technique, and the Johnson-Neyman (floodlight) technique. We sought, as far as possible, to use parametric and nonparametric techniques. It is worth noting that it was not possible to meet all the assumptions for the use of the Multiple Linear Regression technique; however, at the end of the paper, these limitations were itemized. The next topic will present the experiment carried out by this study.

\section{Experiment}

The objective of this study was to analyze the moderation by regulatory focus in the relationship between ego depletion and impulse consumption, 
with emphasis on chronic regulatory focus, which is developed by individuals throughout their lives, through interactions with their parents, relatives, neighbors, etc. In addition, we sought to analyze the relationship between regulatory focus and the affective and cognitive processes of impulse decisions.

\section{Method}

Participants. A total of 146 undergraduate students from a private institution participated in the experiment. The initial sample had 160 respondents; however, some questionnaires were excluded: 5 because they failed the attention test and 9 because they presented errors in completing the data collection instrument. $28.8 \%$ of the participants were female and $69.9 \%$ were male. The average age was $26.39(\mathrm{SD}=21.69)$, the average individual income was $\mathrm{R} \$ 1,002.09$ (SD $=829.10)$, the average per capita income was of $\mathrm{R} \$ 902.90(\mathrm{SD}=1,292.19)$, and $75.30 \%$ of the participants were single.

Design and Procedure. An analysis of the effect of the interaction between two variables was made using a 2 (ego depletion: depleted $v$ s. not depleted) $\mathrm{x}$ continuous (chronic regulatory focus) design by means of floodlight analysis (JohnsonNeyman technique).

The Johnson-Neyman technique (1936) was proposed as an alternative to covariance techniques. Similar to the ANOVA method, the Johnson-Neyman technique is used to examine the conditional effect of an independent variable over a dependent variable for different values of another independent variable (i.e., a moderator variable). Unlike the ANOVA method, the Johnson-Neyman technique requires no transformation of the continuous variables (Tunca, 2016).

According to Spiller, Fitzsimons, Lynch, and McClelland (2013), the Johnson-Neyman point (or points) is the value of the variable for which the floodlight test would reveal a $p$ value of exactly 0.05 . In the case of a 2 x continuous interaction, it is the value of the variable for which the simple effect of $Z$ is statistically significant. The values of the variable on one side of the JohnsonNeyman point generate significant differences between the two groups, while the values on the other side do not. Thus, a floodlight analysis highlights the range of values of the continuous variable for which the differences between the groups are statistically significant.

Initially, a pre-test was performed with a sample of 60 participants; this sample was not part of the final sample of the study. The pretest allowed for the identification of points of improvement in the data collection instrument, with the reduction of some items in the scales. After the pre-test, regulatory focus was measured based on a version adapted from the Regulatory Focus Questionnaire (RFQ) scale of Higgins et al. (2001), using six of the eleven items of the original scale. All items measured in this study, for the different constructs, had the 7-point Likert-type scale in common.

Ego depletion was manipulated through an adaptation of the Baumeister et al. (1998, Study 4) manipulation, using a two-page text on statistics for participants to cross all the letters "e" found in the text. In order to intensify ego depletion, some rules were added to the original manipulation. The following rules were added to the instruction to cross the letters "e": (1) not being close to another vowel; (2) not being the first letter of a word; and (3) not being the last letter of a word. In turn, the participants in the not-depleted-ego condition did not have to follow any additional rules, just the rule of crossing the letters "e". It is believed that following multiple rules causes further self-control expenditure in order to continue performing the task.

To check the manipulation, the following questions were asked: (1) How difficult was it for you to follow the instructions that were given? The answer options ranged from $1=\mathrm{a}$ bit difficult to 7 = very difficult; (2) How much effort did the task require? The answer options ranged from $1=$ little effort to $7=$ a lot of effort.

The mood of the participants was measured using the BMIS adapted scale of Mayer and 
Gashke (1988). Shortly thereafter, the participants answered questions about the affective and cognitive processes of impulse decisions, with a six-item scale adapted from the original Youn scale (2000) adapted by Coley (2002). Demographic data were also collected.

Chocolate tasting was performed using $60 \mathrm{~g}$ of M\&Ms, which were made available so that the participants could evaluate them. This activity was performed for a period of 5 minutes; the participants were told they could eat at ease to be able to evaluate them. In addition, they were informed the chocolate was to be consumed during the activity. Should it not be consumed entirely, the package containing the leftover chocolates was to remain in the same place at the end of the tasting.

Each container had $60 \mathrm{~g}$ of M\&Ms chocolates. All the containers were numbered and weighed before they were given to the participants, and then weighed again at the end of the experiments, using a precision scale. In order to disguise the objective of the tasting, which was to measure the amount consumed, some questions were elaborated to evaluate the quality of the chocolate, related to taste, smell, size, and format, on a scale of $1=$ very bad to $7=$ very good.

A scale adapted from Stunkard and Messick (1985) measured the dietary restrictions of the individuals to serve as a control variable, along with the mood variable. Other variables that were also used as additional control variables were participant weight, hunger intensity, data collection time, healthy diet goals, and dieting. In addition, two questions ended the data collection, in order to evaluate if they had been able to establish the purpose of the research.

\section{I Results}

Manipulation check. To check the manipulation of ego depletion, the participants had to answer two questions after the activity that was aimed at depleting their self-control resources. The non-parametric Mann-Whitney U test (when the variables do not present a normal distribution) was used to test the manipulation check. The participants of the ego-depletion treatment group rated the task as more difficult $\left(\mathrm{M}_{\text {depleted }}=79.36\right.$, $\left.\mathrm{M}_{\text {not_depleted }}=67.48 ; U=2230.50, p<0.05\right)$ and as requiring more effort to be performed $\left(\mathrm{M}_{\text {depleted }}=\right.$ 79.48, $\mathrm{M}_{\text {not_depleted }}=67.35 ; U=2221.50, p<0.05$ ) than the treatment group without ego depletion.

Regulatory focus had no manipulation. The RFQ scale of Higgins et al. (2001) was used to measure the chronic regulatory focus of each participant. The three items that measured the focus on prevention had their scale reversed, so values close to 1 (on the agreement scale of $1=$ totally disagree to $7=$ totally agree) are aligned for this focus, while values close to 7 , in the other three items, are more convergent with the focus on promotion. By means of the Student's $t$ test (since the variables presented a normal distribution), the results show a significant difference in the average of the two focuses, presenting values that support the profile of each focus $\left(\mathrm{M}_{\text {prevention }}=3.15\right.$, $\mathrm{SD}=1.61 ; \mathrm{M}_{\text {promotion }}=4.69, \mathrm{SD}=1.27 ; t(145)=$ $-9.047, p<0.01)$.

Hypothesis testing. In order to test hypotheses $\mathrm{H} 1 \mathrm{a}$ and $\mathrm{H} 1 \mathrm{~b}$, a multiple regression was performed (even though difficulties were found when trying to meet all the assumptions for the use of the technique), with the variables of focus on promotion and prevention for the cognitive process and also for the affective process. Hypothesis H1a was not confirmed because the focus on promotion had no significant effect on the affective process $(t(143)=-0.55, p>0.05)$; in contrast, the focus on prevention presented a significant relationship $(t(143)=2.67, p<0.01)$ to explain this process. In another regression model, now for the cognitive process variable, the regression results showed that the focus on prevention variable had a significant effect to explain the dependent variable $(t(143)=1.74$, $p<0.05)$, but the focus on promotion had no effect $(t(143)=-0.02, p>0.05)$. This result supported hypothesis $\mathrm{H} 1 \mathrm{~b}$.

Regarding depletion of ego, there was a significant difference between the groups for 
this variable, showing that the individuals with depletion consumed more of the chocolate ( $\mathrm{M}$ $=84.78, \mathrm{~N}=74)$ than the individuals without this condition $(\mathrm{M}=61.90, \mathrm{~N}=72, U=1829$, $p<0.01)$. Using the PROCESS Macro model 1 (Hayes, 2013), to test hypothesis $\mathrm{H} 2$, an analysis was performed of the moderating effect of the regulatory focuses $(\mathrm{M})$ in the relationship between ego depletion (X) and chocolate consumption (Y). The regression showed a significant effect of both the focus on promotion $(t(142)=1.67, p<0.05)$ and ego depletion $(t(142)=3.73, p<0.01)$ over chocolate consumption.

The interaction of the variables of ego depletion $($ depleted $=1$, not depleted $=0)$ and the regulatory focus on promotion $(\mathrm{M}=4.69, \mathrm{SD}=$ $1.27)$ with the dependent variable was significant $(t(142)=2.83, p<0.01)$. In order to decompose the interaction, the Johnson-Neyman (floodlight) technique was used to identify the range(s) of the focus-on-promotion variable in which the simple effect of ego-depletion manipulation was significant (for this analysis, according to the technique, a $p$-value of 0.05 was considered). The moderator value that defines the significant Johnson-Neyman region is -0.61 in relation to the average of the focus-on-promotion variable.

Table 1

\section{Floodlight Analysis (Focus on promotion)}

\begin{tabular}{|c|c|c|c|c|c|c|}
\hline Moderator value & B & SE & $\mathbf{T}$ & $\mathbf{P}$ & $\begin{array}{c}\text { Lower limit } \\
95.0 \%\end{array}$ & $\begin{array}{l}\text { Upper limit } \\
95.0 \%\end{array}$ \\
\hline-2.68 & -0.74 & 0.76 & -0.99 & 0.33 & -2.24 & 0.76 \\
\hline-2.44 & -0.57 & 0.70 & -0.82 & 0.42 & -1.95 & 0.82 \\
\hline-2.19 & -0.40 & 0.65 & -0.62 & 0.54 & -1.68 & 0.94 \\
\hline-1.94 & -0.23 & 0.60 & -0.38 & 0.70 & -1.40 & 1.01 \\
\hline-1.69 & -0.06 & 0.54 & -0.11 & 0.92 & -1.13 & 1.09 \\
\hline-1.44 & 0.11 & 0.49 & 0.24 & 0.81 & -0.86 & 1.16 \\
\hline-1.19 & 0.29 & 0.44 & 0.65 & 0.52 & -0.59 & 1.16 \\
\hline-0.94 & 0.46 & 0.40 & 1.16 & 0.26 & -0.33 & 1.25 \\
\hline-0.69 & 0.63 & 0.36 & 1.75 & 0.08 & -0.08 & 1.35 \\
\hline-0.61 & 0.69 & 0.35 & 1.98 & 0.05 & 0.00 & 1.38 \\
\hline-0.44 & 0.81 & 0.33 & 2.45 & 0.02 & 0.16 & 1.46 \\
\hline-0.19 & 0.98 & 0.31 & 3.19 & 0.01 & 0.37 & 1.58 \\
\hline 0.32 & 1.32 & 0.30 & 4.49 & 0.001 & 0.57 & 1.73 \\
\hline 0.57 & 1.49 & 0.31 & 4.87 & 0.001 & 0.74 & 1.90 \\
\hline 0.82 & 1.67 & 0.33 & 5.04 & 0.001 & 0.89 & 2.10 \\
\hline 1.07 & 1.83 & 0.37 & 5.04 & 0.001 & 1.01 & 2.31 \\
\hline 1.31 & 2.01 & 0.41 & 5.07 & 0.001 & 1.12 & 2.55 \\
\hline 1.57 & 2.18 & 0.44 & 4.90 & 0.001 & 1.21 & 2.80 \\
\hline 1.82 & 2.35 & 0.50 & 4.78 & 0.001 & 1.30 & 3.06 \\
\hline 2.07 & 2.52 & 0.55 & 4.66 & 0.001 & 1.45 & 3.59 \\
\hline 2.32 & 2.70 & 0.60 & 4.54 & 0.001 & 1.52 & 3.87 \\
\hline
\end{tabular}

Source: Research Data

This analysis revealed that there was a significant positive effect of the amount of chocolate consumed by the ego-depletion model for any value on the regulatory focus on promotion scale (from 1 to 7$)$ higher than $4.08\left(\beta_{\text {jn }}=0.69, \mathrm{SE}\right.$ $=0.35, p=0.05)$, but not less than 4.08 . 
The regulatory focus on prevention variable $(M=3.15, S D=1.61)$ had no effect on chocolate consumption $(t(142)=-0.35$, $p>0.05)$, but this effect on consumption was found with ego depletion $(t(142)=3.16, p<0.01)$. The interaction of the focus on prevention and ego depletion with the dependent variable was significant $(t(142)=2.22, p<0.05)$. Using the
Johnson-Neyman technique to identify the range of focus on prevention in which ego depletion has a significant effect, a moderating value of -0.69 is found. Thus, the scale value (from 1 to 7 ) of focus on prevention equal to $2.69\left(\beta_{\text {in }}=0.74, \mathrm{SE}=\right.$ $0.37, p=0.05$ ) represents the beginning of the area with a significant effect of chocolate consumption when ego is depleted.

Table 2

Floodlight Analysis (Focus on prevention)

\begin{tabular}{|c|c|c|c|c|c|c|}
\hline $\begin{array}{l}\text { Moderator } \\
\text { value }\end{array}$ & B & SE & $\mathrm{T}$ & $\mathbf{P}$ & $\begin{array}{c}\text { Lower limit } \\
95.0 \%\end{array}$ & $\begin{array}{c}\text { Upper limit } \\
95.0 \%\end{array}$ \\
\hline-2.15 & 0.10 & 0.57 & 0.18 & 0.86 & -1.04 & 1.24 \\
\hline-1.85 & 0.23 & 0.53 & 0.44 & 0.66 & -0.81 & 1.27 \\
\hline-1.55 & 0.36 & 0.48 & 0.75 & 0.45 & -0.58 & 1.31 \\
\hline-1.25 & 0.50 & 0.44 & 1.12 & 0.26 & -0.37 & 1.36 \\
\hline-0.95 & 0.62 & 0.40 & 1.56 & 0.12 & -0.17 & 1.42 \\
\hline-0.69 & 0.74 & 0.37 & 1.98 & 0.05 & 0.00 & 1.47 \\
\hline-0.65 & 0.75 & 0.37 & 2.05 & 0.04 & 0.03 & 1.48 \\
\hline-0.35 & 0.89 & 0.34 & 2.59 & 0.01 & 0.21 & 1.56 \\
\hline-0.05 & 1.02 & 0.33 & 3.13 & 0.001 & 0.52 & 1.78 \\
\hline 0.25 & 1.15 & 0.32 & 3.61 & 0.001 & 0.52 & 1.78 \\
\hline 0.55 & 1.27 & 0.32 & 3.97 & 0.001 & 0.64 & 1.91 \\
\hline 0.85 & 1.41 & 0.34 & 4.20 & 0.001 & 0.75 & 2.07 \\
\hline 1.15 & 1.54 & 0.36 & 4.30 & 0.001 & 0.83 & 2.25 \\
\hline 1.45 & 1.67 & 0.39 & 4.29 & 0.001 & 0.90 & 2.64 \\
\hline 1.75 & 1.80 & 0.43 & 4.23 & 0.001 & 0.96 & 2.85 \\
\hline 2.05 & 1.93 & 0.47 & 4.14 & 0.001 & 1.01 & 2.85 \\
\hline 2.35 & 2.06 & 0.51 & 4.03 & 0.001 & 1.05 & 3.07 \\
\hline 2.65 & 2.20 & 0.56 & 3.93 & 0.001 & 1.09 & 3.30 \\
\hline 2.95 & 2.32 & 0.61 & 3.82 & 0.001 & 1.12 & 3.52 \\
\hline 3.25 & 2.45 & 0.66 & 3.73 & 0.001 & 1.15 & 3.75 \\
\hline 3.55 & 2.58 & 0.71 & 3.64 & 0.001 & 1.18 & 3.99 \\
\hline 3.85 & 2.71 & 0.76 & 3.56 & 0.001 & 1.21 & 4.22 \\
\hline
\end{tabular}

Source: Research Data

When the focus-on-promotion participants reached a score of 4.08 , on the scale that measured this focus, the relationship between ego depletion and chocolate consumption was statistically significant. And when the focus on prevention reached a score of 2.69 , the relationship between ego depletion and chocolate consumption was significant. The value of the regression coefficient $b$ represents the change in output resulting from a unit variation in the input variable. Based on this, by analyzing the $b$ values of the two regulatory focuses, when the p-value is equal to 0.05 , it is possible to notice that for the focus on prevention, ego depletion results in an effect on consumption of 0.74 . For the focus on promotion, ego depletion in the individuals 
had an effect on consumption of 0.69. These results support hypothesis $\mathrm{H} 2$, with a focus on prevention having a greater effect on chocolate consumption than a focus on promotion.

With the inclusion of the mood control variable in the test of the moderating effect of promotion focus in the relationship between ego exhaustion and consumption, it was observed that this variable had no effect on chocolate consumption $(t(141)=-1.15, p>0.05)$. Moreover, the previously found relationship of the regulatory focus on prevention and ego depletion with consumption was not modified. That is, the focus on promotion continued with the marginally significant effect, and ego depletion continued with an effect on the dependent variable. And the moderation test remained significant. For the focus on prevention, the inclusion of the mood variable also had no effect on the previously observed relationship. The mood effect was not significant with regard to the dependent variable $(t(141)=-1.27, p>0.05)$.

The dietary-restriction control variable had a significant effect on consumption $(t(139)=$ $-3.05, p<0.01)$, but did not affect the relationship initially found for the focus on promotion and ego depletion with consumption. The relationship of the focus on prevention and ego depletion with consumption did not change with the inclusion of the healthy-diet-awareness variable. However, this control variable had an effect on consumption $(t(139)=-2.84, p<0.01)$.

Additional tests. The inclusion of other control variables such as weight, time, hunger, and diet had no effect on chocolate consumption and did not change the moderating relationships of the focus on prevention previously found.

Table 3

\section{Other control variables (Focus on prevention)}

\begin{tabular}{lcc}
\hline Variables & $\mathbf{t}$ & $\mathbf{P}$ \\
\hline Participant weight & 0.21 & $>0.05$ \\
Hunger intensity & -1.36 & $>0.05$ \\
Time of data collection & 1.30 & $>0.05$ \\
Healthy diet goal & 1.73 & $<0.05$ \\
Dieting & -0.38 & $>0.05$ \\
\hline
\end{tabular}

Source: Research Data
However, the control variable for the objective of having a healthy diet was significant with regard to the consumption of chocolate, notwithstanding, without changing the moderation relation found previously for the focus on prevention.

Table 4

\section{Other control variables (Focus on promotion)}

\begin{tabular}{lll}
\hline Variables & $\mathbf{t}$ & $\mathbf{P}$ \\
\hline Participant weight & 0.08 & $>0.05$ \\
Hunger intensity & -1.10 & $>0.05$ \\
Time of data collection & 0.89 & $>0.05$ \\
Healthy diet goal & 0.94 & $>0.05$ \\
Dieting & -0.66 & $>0.05$ \\
\hline
\end{tabular}

Source: Research Data

For the focus on promotion, the inclusion of control variables had no effect on chocolate consumption, nor did they change its moderation relationship.

\subsection{Discussion}

Based on the results of the experiment, it was possible to identify that a focus on promotion had an effect on consumption, unlike a focus on prevention. However, the interaction of the two focuses with ego depletion, seeking to analyze the moderating role of the regulatory focus, was significant in explaining the variation in the consumption of chocolate. The results support the hypothesis that in individuals with ego depletion, a focus on prevention has a greater influence on chocolate consumption. Thus, this regulatory focus intensified the impulse consumption of individuals who were already under the influence of a lack of selfcontrol energy. The same did not happen for the individuals with a focus on promotion, who ended up consuming less on impulse.

As mentioned before, the energy expenditure of self-control leaves the individual more susceptible to impulse decisions, due to the absence of self-control willpower (Sjastad \& 
Baumeister, 2018). The studies by Lee and Aaker (2004) emphasize the focus on prevention, when individuals remain vigilant in their decisions to avoid a negative outcome. Based on this premise, it was proposed that a focus on prevention spends more self-control energy. Moreover, in the relationship between ego depletion and impulse consumption, it was predicted by this study that a focus on prevention would have a greater influence on impulse consumption. This prediction was confirmed by the results.

This study also sought to analyze the relationship of the two regulatory focuses with the processes/components of impulse decisions: cognitive and affective. The proposition predicted by this study was not confirmed in relation to a focus on promotion having a greater effect on the affective aspects of impulse decisions. In contrast, the proposition of a focus on prevention having a greater influence on the cognitive aspects was confirmed. These results contribute specifically to the study of the cognitive and affective processes of impulse decisions, since these aspects have been poorly explored in other studies, except for the research by Youn (2000) and Coley and Burgess (2003).

Studies of the affective and cognitive aspects are important because they are involved in opposite situations, but complement each other (Costa, Patriota, \& Angelo, 2017). Understanding the relationship between regulatory focus and the processes makes it possible to understand which of the two focuses would be more prone to impulse consumption, given that the impulsiveness of the individual is related to the balance between the processes. When one of the processes prevails in the control of decisions, the other loses the capacity to influence the outcome (Coley, 2002). As the focus on prevention had a significant effect on both processes (the opposite occurred for the focus on promotion), it is understood that this focus is better able to deal with impulse decisions. However, this statement will only be true for situations without ego depletion, because with the depletion of self-control resources, the focus- on-prevention individuals ended up consuming more than the focus-on-promotion ones.

In addition, as the focus on prevention had an influence over the two impulse decision processes, not only the cognitive process, as originally predicted by this study, it is believed that individuals who act most rationally in their decisions (Katsikeas et al. 2018) are also strongly pressured by the emotional aspects of their decisions. This factor from the affective aspects may have contributed to the focus-on-prevention individuals having had the highest impulse consumption. Because an impulse decision happens when the affective process prevails (Youn, 2002), as both are at equal levels for the focus on prevention, there is no supremacy of the cognitive process. Should it exist, it would imply greater power to decide not to consume.

\section{Conclusion}

This study aimed to analyze the moderating role of chronic regulatory focus in the relationship between ego depletion and impulse consumption, as well as analyzing the relationship between regulatory focus and the affective and cognitive components of impulse decisions. The results found in this study refer to chronic regulatory focus, which is a regulatory behavior developed by the individual throughout his life, through contact with his family and friends (Haws, Dholakia, \& Bearden, 2010).

The main contribution of this research is its counterintuitive result. This statement is based on the relationship that can be established from the findings of the study regarding the daily consumption situations of individuals. The results show that subjects who are supposed to be more prepared to deal with impulse decisions (regulatory focus on prevention) yield to impulse consumption because this profile expends more self-control energies. Thus, for example, for a diet context aimed at weight loss, the more the consumer avoids consuming a tempting food, the more likely he/she will consume this type of product after making some decisions not to do so. 
This behavior of focus-on-prevention individuals of consuming more than those with a focus on promotion can be explained by the former's characteristic of maintaining vigilance in their decisions, which can lead to greater selfcontrol energy expenditure, reaching the limit point of their strength of control, and resulting in an impulse decision. In addition, from analyzing chronic regulatory focus, it is suggested that people may possibly acquire behavioral styles throughout their lives that are more prone to the expenditure of self-control energy, through the influence of family and friends. It is not uncommon to see people who generally avoid strongly negative results, and thus work harder to avoid such situations. And this effort is what leads to a state of lack of energy to maintain self-control in situations when it is necessary.

In this study, focus on prevention was not expected to have a strong relationship with the affective process of impulse decisions, but the results show evidence of this relationship. The relationship found in the research concerning the regulatory focus on prevention with both affective and cognitive aspects can explain impulse decisions. When the affective aspect prevails, compared to the cognitive one, impulse consumption may be more effective, because the willpower to rationalize the decision is diminished. The emotional side drives the individual to act on impulse, i.e., without due deliberation about the decision.

\section{I Implications of the study}

The practical implication of the study lies in it providing a more detailed understanding of consumer self-regulating behavior, which provides support for decision-makers in public organizations. Public policy researchers and decision-makers are often driven towards behavior changes in individuals aiming at improving wellbeing (Haws, Davis, \& Dholakia, 2015). It is suggested that the effectiveness of public policy interventions, and related outcomes, to reduce the problem of self-control failure are dependent on individual differences in the regulatory focuses of consumers.

Thus, a better understanding by public policy managers of the forces that push (and hinder) impulse decisions is critical in order to act more effectively in educational campaigns so as to avoid such decisions. On the other hand, consumers who have access to process information that diminishes their self-control willpower will be more capable of acting to resist the temptations inherent in impulse decisions.

In the current societal context, many health problems are on the rise, such as substance abuse, and impulsive behaviors are exacerbated by a lack of self-regulation (Achtziger et al., 2015). These problems severely hinder the consumer's well-being and represent a tremendous burden on health systems around the world (Hong \& Lee, 2006). For Hong and Lee (2006), while self-help medicines are saturating the market, self-regulation continues to be an arduous process and a constant struggle for many people. Thus, this research may offer substantial guidance for understanding self-control.

It is believed that this research may have implications for consumer well-being. In particular, the results may suggest actions aimed at improving decision-making processes that individuals face on a daily basis, based on the knowledge of their characteristics, involving the two regulatory focuses, which can attenuate impulse decisions. Policies aimed at better quality of life for the consumer can elaborate a general set of prescribed activities that are compatible with the individual's regulatory focus (Aaker $\&$ Lee, 2001; Hong \& Lee, 2006).

\subsection{Research limitations and suggestions for future studies}

One limitation that can be highlighted concerns the place used to perform the manipulations of the independent variables: the classroom. Perhaps an individual site would have been more appropriate because applying the questionnaires to groups of respondents may have 
generated some distractions for the participants. Another limitation that can also be highlighted is related to the use of printed questionnaires. In the handling of these questionnaires, the researchers may have made some typos when organizing the data for analysis. Finally, the results should be considered with parsimony since not all assumptions for the use of the regression technique were met by the data collected. Thus, the tests may present some result distortions.

Recommendations for future research would be to contemplate the use of other constructs, e.g., Kuhl's (1981) state and action orientation, which consists of a theory about the effort made by individuals to achieve their goals. Another theory that can also be used is Lowenstein's theory of automatic and deliberative decision-making.

\section{References}

Aaker, J. L., \& Lee, A. Y. (2001). "I" seek pleasure and "we" avoid pains: The role of self-regulatory goals in information processing and persuasion. Journal of Consumer Research, 28(1), 33-49.

Achtziger, A., Hubert, M., Kenning, P., Raab, G., \& Reisch, L. (2015). Debt out of control: The links between self-control, compulsive buying, and real debts. Journal of Economic Psychology, 49(1), 141-149.

Akhtar, S., \& Lee, J. S. (2014). Assessing factor structure and convergent validity of the work regulatory focus scale. Psychological Reports: Measures \& Statistics, 115(1), 133-147.

Amos, C., Holmes, G. R., \& Keneson, W. C. (2015). A meta-analysis of consumer impulse buying. Journal of Retailing and Consumer Services, 21(2), 86-97.

Avnet, T., \& Higgins, E. T. (2003). Locomotion, assessment, and regulatory fit: value transfer from "how" to "what". Journal of Experimental Social Psychology, 39, 529-530.
Avnet, T., \& Higgins, E. T. (2006). How regulatory fit affects value in consumer choices and opinions. Journal of Marketing Research, 43(1), 1-10.

Badgaiyan, A. J., \& Verma, A. (2015). Does urge to buy impulsively differ from impulsive buying behavior? Assessing the impact of situational factors. Journal of Retailing and Consumer Services, 22(1), 145-157.

Baumeister, R. F., Bratslasky, E., Muraven, M., \& Tice, D. M. (1998). Ego depletion: Is the active self a limited resource? Journal of Personality and Social Psychology, 74(5), 1252-1265.

Baumeister, R. F. (2002). Yielding to temptation: Self-control failure, impulsive purchase, and consumer behavior. Journal of Consumer Research, 28(4), 670-676.

Broonchoo, P., \& Thoumrungroje, A. (2017). A cross-cultural examination of the impact of transformation expectations on impulse buying and conspicuous consumption. Journal of International Consumer Marketing, 29(3), 194-205.

Bullard, O., \& Manchanda, R. V. (2017). How goal progress influences regulatory focus in goal pursuit. Journal of Consumer Psychology, 27(3), 302-317.

Carver, C. S., \& Scheier, M. F. (1990). Principles of self-regulation: action and emotion. In: Higgins, E. T., \& Sorrentino, R. M. (Eds.). Handbook of motivation and cognition: foundations of social behavior (vol. 2). New York: Guilford Press.

Cesario, J., Higgins, E. T., \& Scholer, A. (2008). Regulatory fit and persuasion: basic principles and remaining questions. Social and Personality Psychology Compass, 2(1), 444-463.

Chan, N. C., \& Ho, Y. (2017). The role of regulatory focus and goal progress on goaldirected consumption behaviors. Journal of Consumer Marketing, 34(2), 147-155. 
Coley, A. (2002). Affective and cognitive processes involved in impulse buying. (Master of Science Thesis). The University of Georgia, Athens.

Coley, A., \& Burgess, B. (2003). Gender differences in cognitive and affective impulse buying. Journal of Fashion Marketing and Management, 7(3), 282-295.

Costa, M. F., \& Farias, S. A. (2016). Efeitos da música ao vivo e mecanizada em ambientes de varejos supermercadista. Revista de Administração Contemporânea, 20(2), 154-174.

Costa, M. F., Paula, T. S., Angelo, C. F., \& Fouto, N. M. M. D. (2017). Personalidade da marca, significado do produto e impulsividade na compra por impulso: um estudo em ambiente de shopping center. Revista Eletrônica de Ciência Administrativa, 16, 151-166.

Costa, M. F., Patriota, A., \& Angelo, C. F. (2017). Propagandas de apelo emocional e utilitário: efeitos na atitude do consumidor e na percepção do brand equity de um celular Samsung. Revista de Gestão USP, 24, 268-280.

Dam, Y. K. V., \& Jonge, J. (2015). The positive side of negative labeling. Journal of Consumer Policy, 38, 19-38.

Dholakia, U. M. (2000). Temptation and resistance: an integrated model of consumption impulse formation and enactment. Psychology and Marketing, 17(11), 955-982.

Dholakia, U., Gopinath, M., Bagozzi, R., \& Nataraajan, R. (2006). The role of regulatory focus in the experience and self-control of desire for temptations. Journal of Consumer Psychology, 16(2), 163-175.

Galbraith, J., \& Cummings, L. L. (1967). An empirical investigation of the motivational determinants of task performance: interactive effects between instrumentality - valence and motivation - ability. Organizational Behavior and Human Performance, 2(3), 237-257.
Graham, K. A., Ziegert, J. C., \& Capitano, J. (2015). The effect of leadership style, framing, and promotion regulatory focus on unethical pro-organizational behavior. Journal of Business Ethics, 126, 423-436.

Haws, K. L., Dholakia, U. M., \& Bearden, W. O. (2010). An assessment of chronic regulatory focus measures. Journal of Marketing Research, 47(5), 967-982.

Haws, K. L., Davis, S. W., \& Dholakia, U. M. (2015). Control over what? Individual differences in general versus eating and spending self-control. Journal of Public Policy \& Marketing, 35(1), 37-57.

Hayes, A. F. (2013). Introduction to mediation, moderation, and conditional process analysis. New York: The Guildford Press.

Higgins, T. E., Roney, C. J. R., Crowe, E., \& Hymes, C. (1994). Ideal versus ought predilections for approach and avoidance: distinct self-regulatory systems. Journal of Personality and Social Psychology, 66(2), 276-286.

Higgins, E. T. (1997). Beyond pleasure and pain. American Psychologist, 52(12), 1280-1300.

Higgins, E. T. (2000). Making a good decision: Value from fit. American Psychologist, 55(11), 1217-1230.

Higgins, E. T., Friedman, R. S., Harlow, R. E., Idson, L. C., Ayduk, O. N., \& Taylor, A. (2001). Achievement orientations from subjective histories of success: Promotion pride versus prevention pride. European Journal of Social Psychology, 31, 3-23.

Higgins, E. T., \& Scholer, A. A. (2009). Engaging the consumer: the science and art of the value creation process. Journal of Consumer Psychology, 19, 100-114.

Hong, J., \& Lee, A. Y. (2008). Be fit and be strong: mastering self-regulation through regulatory fit. Journal of Consumer Research, 34(5), 682-695. 
Hur, J. D., Koo, M., \& Hofmann, W. (2015). When temptations come alive: How anthropomorphism undermines self-control. Journal of Consumer Research, 42(2), 340-358.

Johnson, P. O., \& Neyman, J. (1936). Tests of certain linear hypotheses and their application to some educational problems. Statistical Research Memoirs, 1, 57-93.

Itzchakov, G., Uziel, L., \& Wood, W. (2018). When attitudes and habits don't correspond: Selfcontrol depletion increases persuasion but not behavior. Journal of Experimental Social Psychology, $75,1-10$

Katsikeas, C. S., Auh, S., Spyropoulou, S., \& Menguc, B. (2018). Unpacking the relationship between sales control and salesperson performance: a regulatory fit perspective. Journal of Marketing, 82(3), 45-69.

Kuhl, J. (1981). Motivational and functional helplessness: the moderating effect of state versus action orientation. Journal of Personality and Social Psychology, 4O(1), 155-170.

Lai, C. Y., Hsu, J. S. C., \& Li, Y. (2018). Leadership, regulatory focus and information systems development project team performance. International Journal of Project Management, 36(3), 566-582.

Lee, A. Y., \& Aaker, J. L. (2004). Bringing the frame into focus: the influence of regulatory fit on processing fluency and persuasion. Journal of Personality and Social Psychology, 82(6), 205-218.

Lucas, M., \& Koff, E. (2017). Body image, impulse buying, and the mediating role of negative affect. Personality and Individual Differences, 105, 330-334.

Malaviya, P,. \& Brendl, C. M. (2014). Do hedonic motives moderate regulatory focus motives? Evidence from the framing of persuasive messages. Journal of Personality and Social Psychology, 106(1), 1-19.
Manian, N., Papadakis, A., Strauman, T., \& Essex, M. (2006). The developmental of children's ideal and ought self-guides: parenting, temperament, and individual differences in guides strength. Journal of Personality, 74(6), 1619-1645.

Mayer, J. D., \& Gaschke, Y. N. (1988). The experience and meta-experience of mood. Journal of Personality and Social Psychology, 55(1), 102-111.

Montgomery, D. C. (2012). Design and analysis of experiments. 8th ed. Hoboken, NJ: John Wiley \& Sons, 2012.

Mouakhar-Klouz, D., D’Astous, A., \& Darpy, D. (2016). I'm worth it or I need it? Self-gift giving and consumers' self-regulatory mindset. Journal of Consumer Marketing, 33(6), 447-457.

Muraven, M., Tice, D. M., \& Baumeister, R. F. (1998). Self-control as limited resource: regulatory depletion patterns. Journal of Personality and Social Psychology, 74(3), 774-789.

Petrocelli, J. V., Williams, S. A., \& Clarkson, J. J. (2015). The bigger they come, the harder they fall: the paradoxical effect of regulatory depletion on attitude change. Journal of Experimental Social Psychology, 58, 82-94.

Pham, M. T., \& Chang, H. (2010). Regulatory focus, regulatory fit, and the search and consideration of choice alternatives. Journal of Consumer Research, 37(4), 626-640.

Rajat, R. (2017). The effects of regulatory focus and mixed valence imagery and analytical attributes on product decisions, Marketing Intelligence \& Planning, 35(3), 397-407.

Rook, D. W. (1987). The buying impulsive. Journal of Consumer Behavior, 14(2), 189-199.

Rook, D. W., \& Fisher, R. (1995). Normative influences on impulsive buying behavior. Journal of Consumer Research, 22(3), 305-213. 
Salmon, S. J., Vet, E., Adriaanse, M. A., Fennis, B. M., Veltkamp, M., \& Ridder, D. T. D. (2015). Social proof in supermarket: promoting healthy choices under low self-control conditions. Food Quality and Preference, 45, 113-120.

Sengupta, J., \& Zhou, R. (2007). Understanding impulsive eaters choice behaviors: The motivational influences of regulatory focus. Journal of Marketing Research, 44(2), 297-308.

Sjastad, H., \& Baumeister, R. (2018). The future and the will: planning requires self-control, and ego depletion leads to planning aversion. Journal of Experimental Social Psychology, 76, 127-141.

Spiller, S. A., Fitzsimons, G. J., Lynch, J. G., \& McClelland, G. H. (2013). Spotlights, floodlights, and the magic number zero: Simple effects tests in moderated regression. Journal of Marketing Research, 50(2), 277-288.

Stunkard, A. J., \& Messick, S. (1985). The threefactor eating questionnaire to measure dietary restraint, disinhibition, and hunger. Journal of Psychosomatic Research, 29(1), 71-83.

Tabachnick, B. G., \& Fidell, L. S. (2006). Experimental designs using ANOVA. Pacific Grove, CA: Duxbury Press, 2006.
Tunca, B. (2016). Using the Johnson-Neyman Procedure to detect item bias in personality tests: A proposed new method and practical guidelines for data analysis. In U. Kumar (Ed.), The Wiley Handbook of Personality Assessment (pp. 346-360). Hoboken: Wiley-Blackwell.

Verhagen, T., \& Dolen, W. V. (2011). The influence of online store beliefs on consumer online impulse buying: a model and empirical application. Information and Management, 48(8), 320-327.

Vohs, K. D., \& Faber, R. (2007). Spent resources: Self-regulatory resource availability affects impulse buying. Journal of Consumer Research, 33(4), 537-547.

Yim, M. Y. C. (2017). When shoppers don't have enough self-control resources: Applying the strength model of self-control. Journal of Consumer Marketing, 34(4).

Youn, S. (2000). The dimensional structure of consumer buying impulsivity: Measurement and validation. Doctoral Thesis, University of Minnesota, Minneapolis. 


\section{Notes:}

This article is derived from the result of one chapter of the doctoral thesis "The Moderating Role of Regulatory Focus in the Effects of Ego Depletion: a study of impulse consumption decisions", written by Marconi Freitas da Costa, and orientated by Salomão Alencar de Farias, Federal University of Pernambuco, 2016.

\section{Supporting Agencies:}

CAPES/Fulbright

\section{About the Authors:}

Marconi Costa, Phd. in management, Federal University of Pernambuco, Caruaru, Brazil. E-mail: marconi_ costa@hotmail.com

\section{ORCIID}

(iD) 0000-0001-9888-8359

Salomão Farias, Phd. in management, Federal University of Pernambuco, Recife, Brazil. E-mail: saf@ufpe. br

ORCID

(iD) 0000-0001-5415-2606

Claudio Angelo, Phd. in economy, University of São Paulo, São Paulo, Brazil. E-mail: cfa@usp.br

ORCID

(D) 0000-0002-6034-8282

\section{Contribution of each author}

\begin{tabular}{|c|c|c|c|}
\hline Contribution & Marconi Costa & Salomáo Farias & Claudio Angelo \\
\hline 1. Definition of research problem & $\sqrt{ }$ & $\sqrt{ }$ & \\
\hline 2. Development of hypotheses or research questions (empirical studies) & $\sqrt{ }$ & & \\
\hline 3. Development of theoretical propositions (theoretical work) & $\sqrt{ }$ & & \\
\hline 4. Theoretical foundation/Literature review & $\sqrt{ }$ & $\sqrt{ }$ & \\
\hline 5. Definition of methodological procedures & $\sqrt{ }$ & $\sqrt{ }$ & \\
\hline 6. Data collection & $\sqrt{ }$ & & \\
\hline 7. Statistical analysis & $\sqrt{ }$ & & \\
\hline 8. Analysis and interpretation of data & $\sqrt{ }$ & $\sqrt{ }$ & \\
\hline 9. Critical revision of the manuscript & $\sqrt{ }$ & $\sqrt{ }$ & $\sqrt{ }$ \\
\hline 10. Manuscript writing & $\sqrt{ }$ & $\sqrt{ }$ & $\sqrt{ }$ \\
\hline
\end{tabular}

